\title{
The MDG-Human Rights Nexus to 2015 and Beyond
}

\author{
Mary Robinson
}

Abstract Progress has been made in some MDG areas. But in some regions and in many Target areas, progress is overshadowed by the numbers of those left behind and by rising inequalities within and between nations. This article argues that we need better integration of human rights and development and provides some specific ways forward to do this.

\section{Introduction}

We are now well past the halfway mark on the timetable for achieving the UN Millennium Development Goals (MDGs) by 2015. Progress has been made in some areas. The MDGs have generated commitment across governments, international organisations, civil society and the private sector. They have focused attention on key human dimensions of development that more economistic frameworks miss and mobilised many stakeholders around a shared set of objectives that are measurable.

But in some regions and in many Target areas, progress is overshadowed by the numbers of those left behind and by rising inequalities within and between nations. According to the latest UN assessment (UN 2009), there are significant areas where the world is falling short. For example:

- The proportion of people in sub-Saharan Africa living on less than $\$ 1$-a-day is unlikely to be reduced by the Target of one-half.

- One-quarter of all children in developing countries are underweight and are at risk of having a future blighted by the long-term effects of undernourishment.

- Of the 113 countries that failed to achieve gender parity in both primary and secondary school enrolment by the Target date of 2005, only 18 are likely to achieve the Goal by 2015 .

- More than 500,000 prospective mothers in developing countries die annually in childbirth or of complications from pregnancy, a figure that has barely changed since 1990.

- Some 2.5 billion people, almost half the developing world's population, live without improved sanitation.

- More than one-third of the growing urban population in developing countries live in slum conditions, a figure that continues to rise.

Other MDG commitments, such as in the areas of the environment and international cooperation, are also unmet. Carbon dioxide emissions are increasing, foreign aid expenditures are falling short of the Gleneagles commitments, and international trade negotiations, way behind schedule, are not living up to the promise of a 'development' round. In addition, the UN's most recent assessment noted above is based on 2008 data - before the effects of the ongoing global recession were evident and do not account for significant increases in food prices. Both these momentous events have forced tens of millions of people back into poverty in the past $12-18$ months. It is likely, therefore, that when we next take stock of MDG progress at the planned UN Summit in 2010, the picture will be bleak.

\section{The MDGs from a human rights perspective} Critiques of the MDGs from a human rights perspective often point to the lack of focus on the most vulnerable; limited consideration of Goals relating to equality and non-discrimination; and an absence of accountability mechanisms for 
governments in fulfilling obligations they have made to meeting related rights such as health and education. Equally important, the MDGs underemphasise people's own agency - the participation of impoverished people in claiming their rights, and related issues like freedom of information, transparency and access to justice. Moreover, they generally do not give sufficient attention to women's rights or important human rights standards more broadly.

What can be done to close the gap between our ambition and promise to the world's poor, and the results on the ground? Many believe our efforts between now and 2015, as well as our planning for the framework that eventually succeeds the MDGs, must strengthen the linkages between states' human rights commitments and their MDG pledges. There is broad acceptance that current efforts to combat poverty pay too little attention to human rights standards and approaches, just as human rights work appears to deliver very little for the poor. This is a failing not only within the UN, but also among governments, non-governmental organisations (NGOs), and the private sector, where institutions still for the most part approach these interlinked issues as if they were distinct streams of work.

There is an urgent need to ensure that the 2010 Development Summit acknowledges the added value of a human rights and justice framework, and calls for incorporating human rights commitments more squarely into future development strategies.

Exploring the nexus between human rights and development is nothing new, but there is great interest now among governments, civil society and even the business community as the relationship becomes more evident. At the 2005 World Summit, world leaders recognised that the UN's objectives to secure peace, development and human rights were inextricably linked, a recognition that indeed is at the heart of the UN Charter but too often not translated into action.

\section{Integrating human rights and development}

What would greater integration of human rights and development look like in practice? Some specific ways forward are clear. First and foremost, addressing the problem of social exclusion is essential. Those worse off, and members of disadvantaged groups, are in too many cases not making progress, even where aggregate data show overall improvement. As the UN's own analysis (UN 2008: 5) has noted, 'the results to date show that, in most countries, there are usually segments of society that do not share in the benefits without targeted actions to reach them. Government and other actors should therefore pay special attention to any and all at risk of being bypassed by the progress towards the MDGs'. More attention to issues of discrimination and greater focus on the rights of those most excluded would help address this problem. There is an opportunity to address the maternal mortality targets using a more comprehensive approach, for example. The causes of high maternal mortality rates lie not only in weaknesses in government health systems or insufficient donor funding, but also in social factors such as discrimination against women and early marriage. Redoubled efforts using a human rights approach will undoubtedly increase impact in this area.

Second, the success of development efforts depends a great deal on mobilising civil society to work with government to find solutions. How can a stronger focus on human rights give greater scope for such mobilisation - moving away from the 'name and blame' approach to one that is constructive and embeds accountability? Can we create greater demand for fulfilment of human rights, and enable greater capacity by governments to meet those obligations? There are examples of successful partnerships and countries where civil society has mobilised around MDG Targets. For this to happen, it is essential that independent action and rights to organise are protected.

Third, the forces that impact on development are often beyond the power of individual governments acting alone to shape or influence. Issues such as climate change, international trade and investment and infectious diseases, among others, require collective action. We know that the human rights framework, which all governments have agreed to, could provide a benchmark for judging the appropriateness of policies to address such challenges. It would also bring a stronger focus on the problem of accountability where policies of one country impact negatively in others.

Finally, as we contemplate renewing the MDGs and taking steps to establish a post-MDG 
framework in 2015, we should be giving serious consideration to important Goals and Targets that are currently missing but which are undeniably important for achieving development and realising fundamental rights such as increasing efforts to empower women and combat discrimination of all kinds. There should also be greater attention to other issues left aside in 2000, for example improving access to justice and strengthening legal empowerment of the poor.

\section{Notes}

* President, Realizing Rights: The Ethical Globalization Initiative. This Initiative works to put human rights standards at the heart of global governance and policymaking and helps ensure that the needs of the poorest and most vulnerable are addressed on the global stage. It has a particular focus on economic and social rights, and focus on the themes of the right to health, right to decent work,

\section{References}

UN (2009) The MDG Report 2009, New York: United Nations

UN (2008) The MDG Report 2008, New York: United Nations
The challenges of meeting the MDGs and creating a post-2015 framework that harnesses the energies of all actors are significant. Making human rights principles and standards a key part of international development efforts in the years ahead is not only the right thing to do, but if done with real commitment along with broader learning from the 2000-10 period, we will put in place stronger foundations for achieving sustainable and equitable development for people around the world.

corporate responsibility for human rights, promoting women's leadership, and increasingly on climate change and human rights, or climate justice. Realizing Rights (www.realizingrights.org) and Amnesty International (www.amnesty.org/en/demanddignity) are working together and with others to explore institutional and public mechanisms for the ideas contained herein. 